\title{
Morphological traits and RAPD markers for characterization and identification of minor Spanish olive cultivars from the Extremadura region
}

\author{
M.C. Parra-Lobato, F.J. Delgado-Martinez and M.C. Gomez-Jimenez \\ Plant Physiology, Faculty of Science, University of Extremadura, \\ Badajoz, Spain \\ Corresponding author: M.C. Gomez-Jimenez \\ E-mail: mcgomez@unex.es
}

Genet. Mol. Res. 11 (3): 2401-2411 (2012)

Received September 8, 2011

Accepted January 6, 2012

Published May 10, 2012

DOI http://dx.doi.org/10.4238/2012.May.10.6

\begin{abstract}
A total of 91 wild olive accessions and 31 olive cultivars growing in the Extremadura region of central-western Spain were analyzed using morphological traits and RAPD markers. We focused on three main and 16 minor Spanish olive cultivars that are recognized as native or local to the Extremadura region. The five arbitrary 10mer primers tested on the olive cultivars gave 67 polymorphic bands, representing $91 \%$ of the total amplification products. The number of bands per primer ranged from 9 to 18 , whereas the number of polymorphic bands ranged from 8 to 17 . All the cultivars could be identified by a combination of three primers (OPF-6, OPA-8, and OPK-16); four cultivar-specific markers were detected. The minor local "Jariego" and "Tempranillo" cultivars showed the most distal similarities. The resulting dendrogram, using the unweighted pair-
\end{abstract}


group method with arithmetic mean clustering algorithm, depicted the pattern of relationships between the local Extremadura cultivars and the cultivars from geographically connected regions. This analysis showed a correlation between most of the minor local cultivars and the geographical origin; there was no apparent clustering according to morphological traits or fruit use of olive cultivars when these parameters were used as analysis criteria.

Key words: DNA fingerprinting; Genetic diversity; RAPD; Olea europaea

\section{INTRODUCTION}

Olive (Olea europaea L.) is a long-lived evergreen tree that adapts considerably easily to many and varied environmental conditions (Rugini et al., 2011). Cultivated olive is one of the most important orchard species of the Mediterranean basin, representing not only $90 \%$ of the olive cultivation area worldwide but also $90 \%$ of the world's olive production (Rugini et al., 2011). Only 3 countries Spain, Italy, and Greece together account for some $75 \%$ of the olive oil sold worldwide and together with Tunisia and Turkey constitute the 5 largest producers of olive in the world (Rugini et al., 2011). Knowledge of the level and structure of genetic variability are the key steps to manage genetic resources in successful breeding programs, and this is particularly important for olive, for which a high number of different genotypes are currently cultivated (Bracci et al., 2011). Regional analyses, however, remain to be performed, and the information gained is expected to produce crucial insights into the domestication and subsequent crop expansion of olive (Baldoni et al., 2006; Gomez-Jimenez et al., 2006; Bracci et al., 2009; 2011).

The variability of olive in Spain has been widely described on the basis of both morphological and molecular characters (Barranco and Rallo, 2000; Gonzalo-Claros et al., 2000; Sanz-Cortés et al., 2001; Belaj et al., 2004; Rallo et al., 2005; Díaz et al., 2006). Molecular markers such as random amplified polymorphic DNA (RAPD) markers have revealed the wide genetic variability in olive species at the regional (Sanz-Cortes et al., 2001), national (Belaj et al., 2003), and Mediterranean (Belaj et al., 2001) levels. In particular, cultivars from small areas (provinces or regions of Spain) were grouped according to the geographical origin by using RAPD markers (Gonzalo-Claros et al., 2000; Sanz-Cortes et al., 2001), and no apparent clustering was observed according to fruit size or other morphological characters (Sanz-Cortez et al., 2001).

The Extremadura region (central-western Spain) includes areas having a broad range of environments, climates, and soils. This region has substantial production of olive oil and table olives primarily from 21 autochthonous or local cultivars from a total of 40 cultivars currently distributed in the different agro-ecological areas (Delgado-Martinez, 2006). The "Morisca", "Verdial de Badajoz", "Manzanilla Cacereña", "Manzanilla Carrasqueña", "Cornicabra", and "Pico Limón" cultivars represent $80 \%$ of the Extremadura olive heritage (Delgado-Martinez, 2006). These cultivars have been previously identified by using morphological traits (Rallo et al., 2005) and RAPD (Belaj et al., 2004) and SSR (Díaz et al., 2006; DelgadoMartinez et al., 2011) markers. Recently, high genetic diversity has been detected among 25 
olive cultivars grown in the Extremadura region by using SSR markers (Delgado-Martinez et al., 2011). The high diversity of cultivars, considering the small area of cultivation, is probably due to their indigenous origin and reduced selection pressure by farmers throughout history (Delgado-Martinez, 2006). The other $20 \%$ of the olive heritage consists of 16 minor local cultivars from specific areas depending on their degree of importance and diffusion (DelgadoMartinez, 2006). Study of genetic resources and discrimination of Extremadura minor cultivars are particularly important for preserving the biodiversity and maintaining the advantages of local cultivars. However, little is known about the minor cultivars of this region and the genetic relationships among them.

To identify the minor Spanish olive cultivars of regional origin, which are well adapted to local conditions, we used morphological traits and RAPD markers to fingerprint and assess the genetic diversity of the minor olive cultivars from the Extremadura region, as well as to determine their genetic relationships with the main cultivars from this region and from geographically connected regions.

\section{MATERIAL AND METHODS}

\section{Plant material, DNA extraction, and morphological trait analysis}

A panel of 91 accession numbers belonging to 32 olive cultivars were used. These cultivars were grown in the Extremadura region (central-western Spain) and collected from their orchards (Table 1). These included a wild type O. europaea sylvestris ("WT"), 19 cultivars recognized as native or local to Extremadura (3 main and 16 minor local cultivars), and 12 introduced or foreign cultivars from Portugal ("Galega", "Cordovil", "Carrasqueña", and "Redondil"), southern Spain ("Manzanilla Sevillana", "Ocal", "Hojiblanca", "Bical", "Limoncillo", and "Picual"), north-eastern Spain ("Arbequina"), and central Spain ("Cornicabra"). The precise geographical location of the collection sites is available on request. Where possible, 10 different trees were sampled at each site in order to represent the maximal genetic diversity occurring in an accession.

Total DNA was extracted from young leaves of these cultivars as described by Belaj et al. (2001). For the morphological description of olive leaf, fruit, and pit, 4, 9, and 2 characters were selected, respectively (Table 2 ), from the pomological pattern widely used for olive cultivar characterization (Rallo et al., 2005).

\section{RAPD analysis}

After decamer oligonucleotides from kits A, C, K, R, S, X, and Z of Operon Technologies (Alameda, CA, USA) were screened by polymerase chain reaction (PCR) amplification, DNA was amplified using the reaction mixtures described by Cordeiro et al. (2008). The PCRs were performed in a thermal cycler (GeneAmp PCR System 9600; Applied Biosystems) programmed for 1 cycle of $1 \mathrm{~min}$ at $94^{\circ} \mathrm{C}$, followed by 40 cycles of $30 \mathrm{~s}$ at $94^{\circ} \mathrm{C}, 30 \mathrm{~s}$ at $35^{\circ} \mathrm{C}$, and $2 \mathrm{~min}$ at $72^{\circ} \mathrm{C}$, for denaturing, primer annealing, and extension, respectively. The last cycle was followed by incubation for $7 \mathrm{~min}$ at $72^{\circ} \mathrm{C}$. All the reactions were performed 3 times by using DNA of different extractions and different lots of the AmpliTaq DNA polymerase (Amersham Pharmacia Biotech). 


\section{Data analysis}

RAPD bands were scored as 1 (present) or 0 (absent) in a binary matrix. A conservative criterion for the selection of bands and reproducible and well-defined bands in each of the 3 replications were considered for the analysis. Jaccard's similarity coefficient (Jaccard, 1908) was calculated. The cultivars were grouped by cluster analysis by using the unweighted pairgroup method (UPGMA). The data were analyzed using NTSYS-pc version 2.02 (Rohlf, 1998).

\section{RESULTS AND DISCUSSION}

In all, 91 accessions belonging to 32 olive cultivars, including 34 accessions of 16 minor olive cultivars grown on the Extremadura region (central-western Spain), were analyzed using 5 RAPD markers (Table 1). The total number of bands and the number of polymorphic bands of each of the 5 primers selected are shown in Table 3 . Of a total of 73 reproducible amplified bands, 67 were polymorphic, constituting a large number $(91.30 \%)$ of polymorphisms. The number of bands per primer ranged from 9 (OPF-6) to 18 (OPA-8), whereas the number of polymorphic fragments varied per marker from 8 (OPF-6) to 17 (OPA-8). These values indi-

Table 1. Number of accessions analysed of 32 olive cultivars used in this study with code number, use of fruits, and cultivar typology..

\begin{tabular}{|c|c|c|c|c|}
\hline Code & Cultivar name & Accession No. & Use / Diffusion area & Typology \\
\hline 2 & "Carrasqueña" & 4 & $\mathrm{O} / \mathrm{C}-\mathrm{S}$ area & Foreign cultivar \\
\hline 4 & "Oliva"" & 3 & $\mathrm{O} / \mathrm{S}$ area & Local cultivar (minor cultivar) \\
\hline 5 & "Morisca" & 4 & $\mathrm{O} / \mathrm{C}-\mathrm{S}$ area & Local cultivar (main cultivar) \\
\hline 6 & "Pico Limon" & 4 & $\mathrm{O} / \mathrm{S}$ area & Local cultivar (main cultivar) \\
\hline 9 & "Pico Real" & 2 & $\mathrm{O} / \mathrm{S}$ area & Local cultivar (minor cultivar) \\
\hline 11 & “Azulejo" & 3 & $\mathrm{O} / \mathrm{S}$ area & Local cultivar (minor cultivar) \\
\hline 12 & "Perito" & 2 & $\mathrm{O} / \mathrm{S}$ area & Local cultivar (minor cultivar) \\
\hline 13 & "Manzanilla Real" & 3 & $\mathrm{O}-\mathrm{T} / \mathrm{C}$ area & Local cultivar (minor cultivar) \\
\hline 19 & "Redondil" & 4 & $\mathrm{O} / \mathrm{C}-\mathrm{S}$ area & Foreign cultivar \\
\hline 20 & "Cordovil" & 3 & $\mathrm{O} / \mathrm{C}$ area & Foreign cultivar \\
\hline 24 & "Ocal" & 2 & $\mathrm{O} / \mathrm{C}-\mathrm{S}$ area & Foreign cultivar \\
\hline 25 & "Colora" & 2 & $\mathrm{O} / \mathrm{C}$ area & Local cultivar (minor cultivar) \\
\hline 34 & “Cañaval” & 2 & $\mathrm{O} / \mathrm{S}$ area & Local cultivar (minor cultivar) \\
\hline 35 & "Tempranillo" & 2 & $\mathrm{O} / \mathrm{S}$ area & Local cultivar (minor cultivar) \\
\hline 41 & "Galega" & 3 & $\mathrm{O}-\mathrm{T} / \mathrm{C}$ area & Foreign cultivar \\
\hline 44 & "Pajonala" & 3 & $\mathrm{O} / \mathrm{N}-\mathrm{C}$ area & Local cultivar (minor cultivar) \\
\hline 45 & "Bical" & 2 & $\mathrm{O}-\mathrm{T} / \mathrm{N}-\mathrm{C}$ area & Foreign cultivar \\
\hline 47 & "Limoncillo" & 3 & $\mathrm{O} / \mathrm{C}$ area & Foreign cultivar \\
\hline 48 & "Corniche" & 2 & $\mathrm{O} / \mathrm{C}$ area & Local cultivar (minor cultivar) \\
\hline 52 & "Azulito" & 2 & $\mathrm{O} / \mathrm{S}$ area & Local cultivar (minor cultivar) \\
\hline 56 & "Jariego" & 2 & $\mathrm{O} / \mathrm{S}$ area & Local cultivar (minor cultivar) \\
\hline 74 & "Hojiblanca" & 3 & $\mathrm{O} / \mathrm{C}$ area & Foreign cultivar \\
\hline 84 & "Manzanilla Cacereña" & 4 & $\mathrm{O}-\mathrm{T} / \mathrm{N}$ area & Local cultivar (main cultivar) \\
\hline 92 & "Manzanilla Sevillana" & 4 & $\mathrm{~T} / \mathrm{S}$ area & Foreign cultivar \\
\hline 93 & "Cornicabra" & 4 & $\mathrm{O} / \mathrm{N}-\mathrm{C}$ area & Foreign cultivar \\
\hline 95 & "Redondillo" & 3 & $\mathrm{O} / \mathrm{C}-\mathrm{S}$ area & Local cultivar (minor cultivar) \\
\hline 98 & "Cuerno Real" & 3 & $\mathrm{O} / \mathrm{S}$ area & Local cultivar (minor cultivar) \\
\hline 100 & "WT" & 3 & $\mathrm{O} / \mathrm{C}$ area & Wild trees \\
\hline 104 & "Picual" & 3 & $\mathrm{O} / \mathrm{C}$ area & Foreign cultivar \\
\hline 105 & "Arbequina" & 3 & $\mathrm{O} / \mathrm{C}$ area & Foreign cultivar \\
\hline 114 & "Original" & 2 & $\mathrm{~T} / \mathrm{C}$ area & Local cultivar (minor cultivar) \\
\hline 115 & "Cojón del Gallo" & 2 & $\mathrm{O} / \mathrm{C}-\mathrm{S}$ area & Local cultivar (minor cultivar) \\
\hline
\end{tabular}

$\mathrm{O}=$ oil $; \mathrm{T}=$ table olive; $\mathrm{O}-\mathrm{T}=$ oil and table olive, diffusion area in Extremadura $\mathrm{C}=$ center; $\mathrm{N}=$ north; $\mathrm{S}=$ south. 


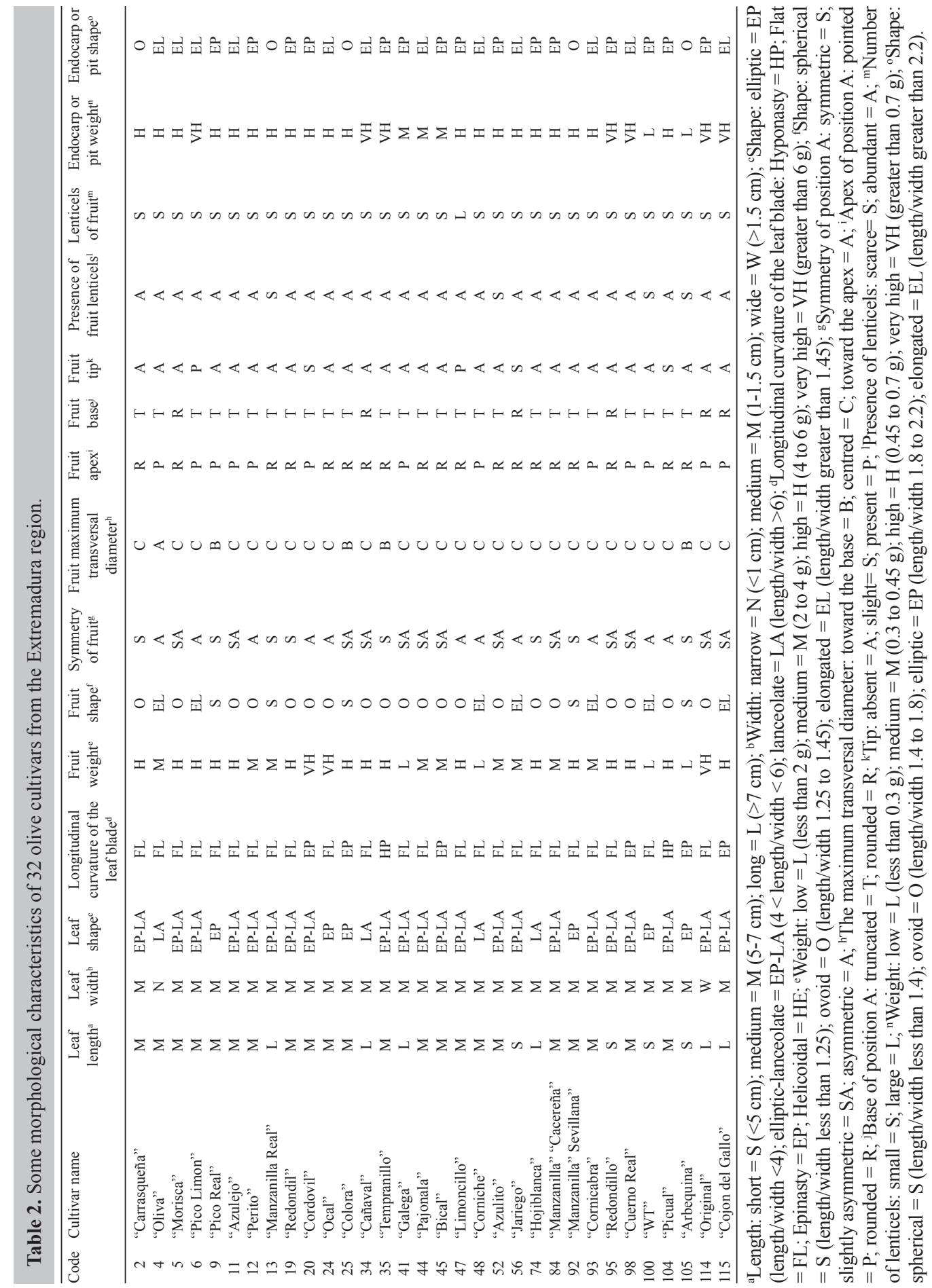


cated that the RAPD markers effectively differentiated the olive cultivars studied. In addition, no differences were found between the amplification profiles of the different individuals of the same cultivar. The high level of polymorphism observed in this study is in agreement with the results of previous studies on Spanish olive cultivars conducted using RAPD (Sanz-Cortés et al., 2001; Belaj et al., 2004) and SSR (Díaz et al., 2006; Sarri et al., 2006; Delgado-Martinez et al., 2011) markers.

Table 3. Level of polymorphism found by the RAPD analysis.

\begin{tabular}{lccc}
\hline Primer & TNB & NPB & P [\%] \\
\hline OPA 08 & 18 & 17 & $94.44 \%$ \\
OPA 11 & 16 & 14 & $87.50 \%$ \\
OPF 06 & 9 & 8 & $88.88 \%$ \\
OPX 06 & 14 & 12 & $85.71 \%$ \\
OPK 16 & 16 & 16 & $100.00 \%$ \\
Average & 14.60 & 13.40 & $91.30 \%$ \\
Total & 73 & 67 & \\
\hline TNB = total number of bands; NPB = number of polymorphic bands; P = percentage of polymorphic band.
\end{tabular}

All 32 cultivars were identified by different combinations of band patterns found for the 5 primers. Of the 73 polymorphic bands, some were specific to a given cultivar. The minor local "Cuerno Real", "Manzanilla Real", and "Perito" cultivars, and main local "Morisca" cultivar were univocally identified by a single marker (Table 4). The marker OPA-08 (275 bp) was exclusively absent in the cultivar "Cuerno Real", whereas the markers OPA8-10 (400 bp), OPK16-4a (675 bp), and OPF6-2a (725 bp) appeared only in the cultivars "Morisca", "Manzanilla Real", and "Perito", respectively. For identification purposes, the genotype-specific markers provide useful information. In particular, the OPA8-10 single marker was potentially informative in distinguishing the "Morisca" cultivar, a major Extremadura cultivar of great economic importance used for oil production, with large-sized fruits of ovoid-shape and elongated endocarps (Table 2). Therefore, 4 specific markers were detected in this study, each corresponding uniquely to "Morisca", "Manzanilla Real", "Perito", and "Cuerno Real". These markers represented the genotype-specific markers. For the identification of cultivars that did not present single markers, a combination of 2 or 3 markers was needed. With the combination of only 3 primers (OPF-6, OPA-8, and OPK-16), all the cultivars studied could be identified.

\begin{tabular}{llc}
\multicolumn{2}{l}{ Table 4. Four genotype-specific RAPD } & \\
\hline Code & Name of cultivar & RAPD marker \\
\hline 98 & "Cuerno Real" & OPA 08 (275 bp) \\
5 & "Morisca" & OPA 08 (400 bp) \\
13 & "Manzanilla Real" & OPK 16 (675 bp) \\
12 & "Perito" & OPF 06 (725 bp) \\
\hline
\end{tabular}

High variability was found in the frequency of polymorphic bands for the cultivars studied (data not shown). A relatively high percentage (40.6\%) of pairs of cultivars shared low similarity coefficient values $(<0.6)$, and only $6.25 \%$ shared a relatively high similarity $(>0.8)$. In general, these low similarity values confirmed the hypothesis of a high degree of diversity among local Extremadura olive cultivars, due to their indigenous origin and reduced pressure of selection by farmers throughout history (Belaj et al., 2003; Delgado-Martinez et al., 2011). 
High levels of genetic diversity have also been found for the main olive cultivars disseminated in Extremadura or other regions of Spain (Barranco and Rallo, 2000; Gonzalo-Claros et al., 2000; Sanz-Cortés et al., 2001; Belaj et al., 2004).

RAPD and morphological analysis are 2 phenotypic methods that could be combined for cultivar identification. The morphological characters of each cultivar were collected according to the pomological pattern widely used for characterizing olive cultivars (Rallo et al., 2005). The morphological characterization discriminated the olive cultivars grown in the Extremadura region, and all the 16 minor local cultivars differed according to the morphological assay on the basis of leaf, fruit, and endocarp criteria (Table 2). Among the minor local cultivars, "Jariego" had the smallest and "Original" had the widest and longest leaves; "Corniche" had the smallest fruits, whereas "Original" also had the biggest fruits; and "Pajonala" has the smallest endocarps, whereas "Original" also had the biggest endocarps (Table 2).

The lowest similarity values were found for the cultivars "Jariego" and "Tempranillo" $(0.24)$ and "WT" and "Tempranillo" $(0.30)$, whereas the highest values were found for "Ocal" and "Colora" (0.80), "Morisca" and "Redondillo" (0.75), and "Pico Real" and "Cojon del Gallo" (0.72) cultivars. In fact, "WT" differed from all the other cultivars both with regard to the molecular and morphological characters (Table 2). Similarly, the minor local cultivars "Jariego" and "Tempranillo" exhibited morphological differences in leaf, fruit, and endocarp. However, the highest values of similarity between the cultivars did not coincide with similar morphological traits (Table 2). On the other hand, 3 cultivars, namely, "Manzanilla" were studied: "Manzanilla Sevillana" (foreign cultivar), "Manzanilla Cacereña" (main local cultivar), and "Manzanilla Real" (minor local cultivar). The similarity values (0.46-0.54) of the "Manzanilla" cultivars can be considered medium to low, indicating that a shared denomination among certain cultivars due to a common characteristic does not signify high genetic similarity, as observed between the "Manzanilla" cultivars from Spain and Portugal (Belaj et al., 2004; Cordeiro et al., 2008). The results showed that the best agreement between the morphological traits and RAPD analysis was found for cultivar pairs with a low similarity coefficient.

Previous studies performed using morphological and agronomical traits (Barranco and Rallo, 2000; Rallo et al., 2005) as well as molecular analysis by RAPD markers (Sanz-Cortés et al., 2001; Belaj et al., 2004) have confirmed the diversity of Spanish olive germplasm. Nevertheless, most of the genotypes determined in these studies corresponded to the main cultivars from Spain. In the present study, of the 19 genotyped local cultivars from Extremadura, only 3 local cultivars ("Morisca", "Manzanilla Cacereña", and "Pico Limon") coincided with those of previous studies; thus, a direct comparison of the results was not feasible.

In Extremadura, as per the morphological description, 16 different minor olive cultivars among the 21 local cultivars have been suggested (Delgado-Martinez, 2006). The present study was undertaken to test the morphological differences in the local cultivars from Extremadura by using RAPD markers, and this analysis unambiguously discriminated all the 16 minor local cultivars. Recently, we used SSR markers and reported the molecular identification of 10 minor local cultivars from Extremadura (Delgado-Martinez et al., 2011). These new additions to the list of minor olive cultivars would enrich and preserve local genetic resources and contribute to an overall understanding of regional olive germplasm in Spain.

The relatedness of the cultivars studied was efficiently established by using RAPD markers. The dendrogram resulting from the UPGMA method (Figure 1) indicated clear differences among all the cultivars, with the similarity coefficients between all possible pairs 
of genotypes ranging from 0.24 to 0.80 . The genetic analysis of the results showed a gradual distance between the cultivars, making it difficult to identify a well-differentiated phylogenetic group. This classification based on RAPD markers could not be related to known morphological information about the cultivars, and no particular aggregation related to morphological traits was observed.

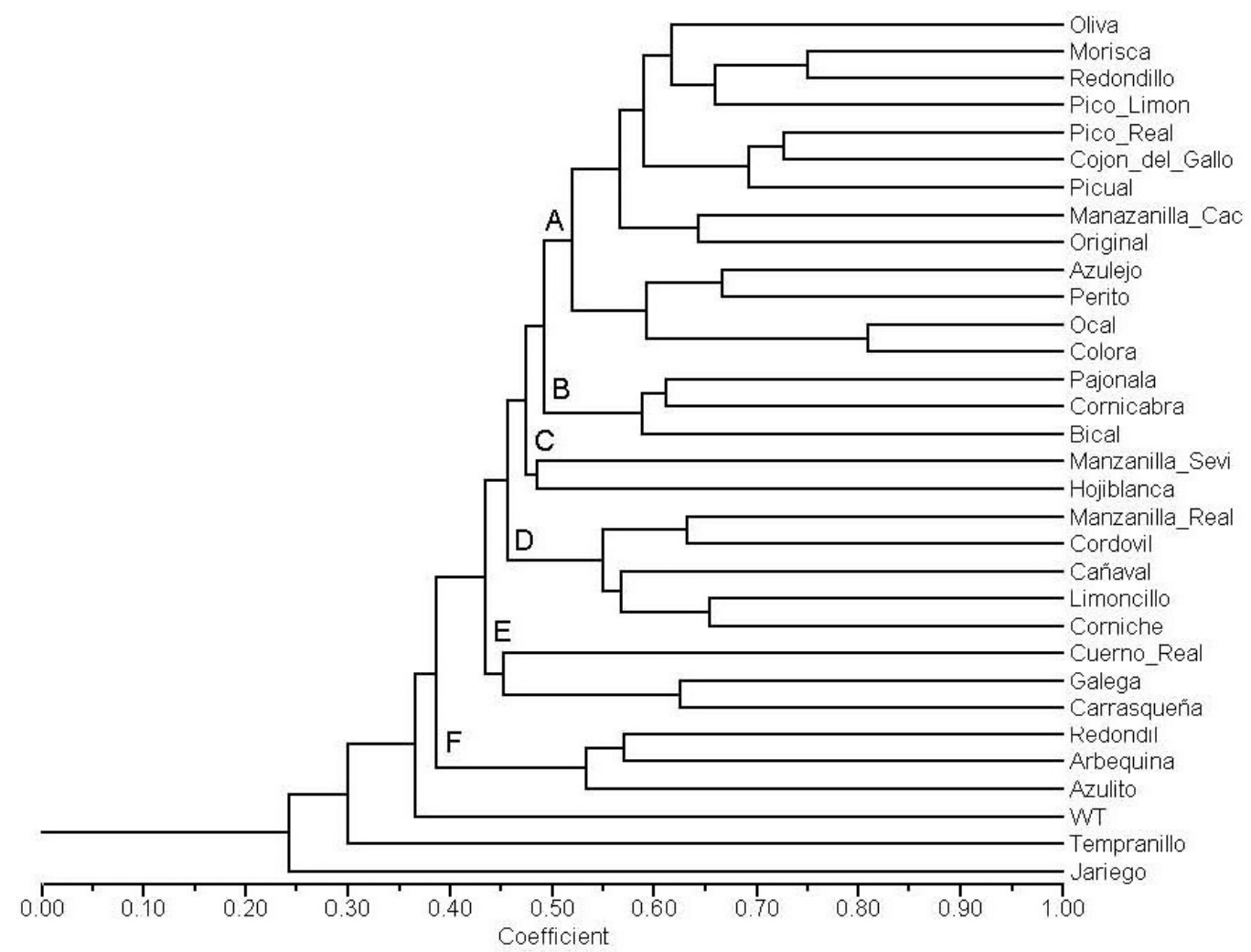

Figure 1. Dendogram of olive cultivars using UPGMA clustering methods and Jaccard's similarity index.

For a similarity coefficient higher than 0.40 , differentiating 6 main groups (A, B, C, $\mathrm{D}, \mathrm{E}$, and $\mathrm{F}$ ) was possible, whereas 3 cultivars remained quite unrelated either to each other or to the previous groups ("WT", "Tempranillo", and "Jariego" cultivars). The different position of "Tempranillo" and "Jariego", minor local cultivars, in comparison to the other cultivars, suggests that they have a different origin. "Tempranillo" and "Jariego" cultivars were the most differentiated from the other minor local cultivars (Figure 1) and are locally cultivated in southern Extremadura (used for oil). Group A consisted of 13 cultivars, with an average similarity of 0.65. Except "Picual" and "Ocal" (foreign cultivars from southern Spain), all cultivars of group A were local cultivars, including 8 minor cultivars from Extremadura. In this group, the highest similarity coefficients were found between "Ocal" and "Colora", "Morisca" and "Redondillo", well as well "Pico Limon" and "Pico Real" $(0.80,0.75$, and 0.72 of similarity, 
respectively). The latter 2 cultivars, grown in the south of the region for oil production, also had a high similarity coefficient when analysed using SSR markers (Delgado-Martinez et al., 2011). All the minor local cultivars of group A are used for oil production, except the cultivar "Original". This minor cultivar, with the highest endocarp weight and fruit weight, was used for table olives, as opposed to the rest of minor local cultivars. "Original" registered the highest similarity (0.60) with another local cultivar for table olives - "Manzanilla Cacereña" (main cultivar) - with ellipsoidal endocarps and ovoid fruits having a slightly asymmetric position "A" (Table 2). Within group A, 2 distinct subgroups (A1 and A2) were clearly defined. Subgroup A1 consisted of 9 cultivars ( 5 minor, 3 main local, and 1 foreign cultivar), whereas subgroup A2 consisted of 4 cultivars ( 3 minor local and 1 foreign cultivar). In general, low similarity coefficients were found among the cultivars of these 2 subgroups.

Group B consisted of foreign cultivars ("Cornicabra" and "Bical") except "Pajonala" (minor local cultivar for oil production) with a similarity value of 0.60 (Figure 1). "Pajonala" was morphologically similar to another local cultivar "Morisca" (main cultivar used for oil), with ellipsoidal endocarps and ovoid fruits that differed only with regard to the position "A" of the fruit (Table 2). Both cultivars of group C, i.e., "Manzanilla Sevillana" and "Hojiblanca" (similarity value, 0.50 ), were foreign cultivars from southern Spain used for table and oil olive, respectively, and have large-sized fruits and endocarps. Group D contained 3 minor local cultivars ("Manzanilla Real", "Cañaval", and "Corniche") with 2 foreign cultivars "Cordovil" and "Limoncillo". Group E consisted exclusively of foreign main cultivars from Portugal, except a minor local cultivar from Extremadura "Cuerno Real". Group F consisted of the foreign cultivars "Arbequina" and "Redondil" from northern Spain and Portugal, respectively, with the minor local cultivar "Azulito" (similarity value, 0.53 ) from southern Extremadura (Figure 1).

In Extremadura, olives are cultivated throughout the region under different edaphoclimatic conditions. The local Extremadura cultivars did not cluster independently from cultivars originating from Portugal and other Spanish regions: 10 of the 21 local cultivars constituted a group with a cultivar from southern Spain; "Pajonala", a local cultivar, formed a branch with 2 cultivars from central and southern Spain; local cultivars "Manzanilla Real", "Cañaval", and "Corniche" clustered with 2 cultivars from Portugal and southern Spain; "Cuerno Real", a local cultivar, formed a branch with 2 cultivars from Portugal; and the local cultivar "Azulito" clustered with 2 cultivars from Portugal and northern Spain. Moreover, 4 of 16 minor local cultivars from Extremadura were more similar to the cultivars from Portugal than those from their own country. These results agree with those of previous studies performed using molecular markers, in which a clustering of olive cultivars from different geographic origins had been observed (De Caraffa et al., 2002; Belaj et al., 2003; Owen et al., 2005). However, the most minor local cultivars (10 out of 16) formed a group (group A) with the main local cultivars from Extremadura (Figure 1). These results showed a separation between most cultivars from Extremadura and those from other regions of Spain and Portugal. Group A consisted exclusively of cultivars originating from Extremadura, except 2 cultivars from southern Spain. The clustering of the cultivars from the same or nearby regions suggests a common genetic base and an autochthonous origin for these cultivars. This result agrees with the hypothesis of autochthonous origin of most of the olive cultivars as well as their limited spread from their centers of origin (Barranco and Rallo, 2000; Besnard et al., 2001; Belaj et al., 2001, 2003). Therefore, this implies that the relationships for most minor cultivars from Extremadura according to their geographic origin agree with our prior findings obtained using SSR markers 
(Delgado-Martinez et al., 2011). Within Spain, olive cultivars from small areas have also been grouped using RAPD markers on the basis of geographical origin (Gonzalo-Claros et al., 2000), and an independent and local selection of Spanish olive cultivars at the regional level has be indicated (Belaj et al., 2004). Recently, the current diversity found in Spanish olive cultivars might be regionally differentiated using SSR markers, and this supported the hypothesis of both an autochthonous and allochthonous origin (Belaj et al., 2010).

In conclusion, our results showed a correlation between the most minor local cultivars and the geographical origin, and that RAPD markers combined with morphological traits could be used to identify and discriminate the minor Spanish olive cultivars from the Extremadura region that enrich and preserve the local genetic resources.

\section{ACKNOWLEDGMENTS}

Research supported by grants from the "Ministerio de Ciencia e Innovacion", Spain (BFU2007-62566 and BFU2010-18116). FJ Delgado-Martinez was granted a fellowship from the University of Extremadura (Spain).

\section{REFERENCES}

Baldoni L, Tosti N, Ricciolini C, Belaj A, et al. (2006). Genetic structure of wild and cultivated olives in the central Mediterranean basin. Ann. Bot. 98: 935-942.

Barranco D and Rallo L (2000). Olive cultivars in Spain. Hort. Technol. 10: 107-110.

Belaj A, Trujillo I, De la Rosa R and Rallo L (2001). Polymorphism and discrimination capacity of randomly amplified polymorphic markers in an olive germplasm bank. J. Am. Soc. Hort. Sci. 126: 64-71.

Belaj A, Satovic Z, Cipriani G, Baldoni L, et al. (2003). Comparative study of the discriminating capacity of RAPD, AFLP and SSR markers and of their effectiveness in establishing genetic relationships in olive. Theor. Appl. Genet. 107: 736-744.

Belaj A, Satovic Z, Trujillo I and Rallo L (2004). Genetic relationships and partition of variability of Spanish olive cultivars by means of RAPD markers. Hort. Sci. 39: 948-951.

Belaj A, Muñoz-Diez C, Baldoni L, Satovic Z, et al. (2010). Genetic diversity and relationships of wild and cultivated olives at regional level in Spain. Sci. Hort. 124: 323-330.

Besnard G, Baradat P and Bervillé A (2001). Genetic relationships in the olive (Olea europaea L.) reflect multilocal selection of cultivars. Theor. Appl. Genet. 102: 251-258.

Bracci T, Sebastiani L, Busconi M, Fogher C, et al. (2009). SSR markers reveal the uniqueness of olive cultivars from the Italian region of Liguria. Sci. Hort. 122: 209-215.

Bracci T, Busconi M, Fogher C and Sebastiani L (2011). Molecular studies in olive (Olea europaea L.): overview on DNA markers applications and recent advances in genome analysis. Plant Cell Rep. 30: 449-462.

Cordeiro AI, Sanchez-Sevilla JF, Alvarez-Tinaut MC and Gomez-Jimenez MC (2008). Genetic diversity assessment in Portugal accessions of Olea europaea by RAPD markers. Biol. Plant. 52: 642-647.

De Caraffa VB, Maury J, Gambotti C, Breton C, et al. (2002). Mitochondrial DNA variation and RAPD mark oleasters, olive and feral olive from Western and Eastern Mediterranean. Theor. Appl. Genet. 104: 1209-1216.

Delgado-Martinez FJ (2006). Caracterización y Desarrollo de Marcadores Moleculares SSR para la Identificación de Variedades Autóctonas de Olivo en Extremadura. Master's thesis, University of Extremadura, Badajoz.

Delgado-Martinez FJ, Amaya I, Sanchez-Sevilla JF and Gomez-Jimenez MC (2011). Microsatellite marker-based identification and genetic relationships of olive cultivars from the Extremadura region of Spain. Genet. Mol. Res. 11: 918-932.

Díaz A, De la Rosa R, Martín A and Rallo P (2006). Development, characterization and inheritance of new microsatellites in olive (Olea europaea L.) and evaluation of their usefulness in cultivar identification and genetic relationship studies. Tree Genet. Genomes 2: 165-175.

Gomez-Jimenez MC, Cordeiro AI, Espinosa F and Alvarez-Tinaut MC (2006). Las Variedades de Olivo en Portugal. 
Universidad de Extremadura, Cáceres.

Gonzalo-Claros M, Crespillo R, Aguilar ML and Cánovas FM (2000). DNA fingerprinting and classification of geographically related genotypes of olive-tree (Olea europaea L.). Euphytica 116: 131-142.

Jaccard P (1908). Nouvelle recherches sur la distribution florale. Bull. Soc. Vaud. Sci. Nat. 44: 223-270.

Owen CA, Bita EC, Banilas G, Hajjar SE, et al. (2005). AFLP reveals structural details of genetic diversity within cultivated olive germplasm from the Eastern Mediterranean. Theor. Appl. Genet. 110: 1169-1176.

Rallo L, Barranco D, Caballero JM, Del Rio C et al. (2005). Variedades de Olivo en España. Junta de Andalucia. MAPA y Ediciones Mundi-Prensa, Madrid.

Rohlf FJ (1998). NTSYS-pc. Numerical Taxonomy and Multivariate Analysis System, Version 2.00. Exeter Software. Setauket.

Rugini E, De Pace C, Gutierrez-Pesce P and Muleo R (2011). Olea. In: Wild Crop Relatives: Genomic and Breeding Resources, Temperate Fruits (Kole C, ed.). Springer-Verlag Berlin Heidelberg., Berlin.

Sanz-Cortéz F, Badenes ML, Paz S, Íñiguez A, et al. (2001). Molecular characterization of olive cultivars using RAPD markers. J. Am. Soc. Hort. Sci. 126: 7-12.

Sarri V, Baldoni L, Porceddu A, Cultrera NG, et al. (2006). Microsatellite markers are powerful tools for discriminating among olive cultivars and assigning them to geographically defined populations. Genome 49: 1606-1615. 